\title{
Nutritional assessment methods as predictors of postoperative mortality in gastric cancer patients submitted to gastrectomy
}

\section{Métodos de avaliação nutricional preditores de mortalidade pós-operatória em pacientes submetidos à gastrectomia por câncer gástrico}

Aline Kirjner Poziomyck'; ' Leandro Totti Cavazzola, TCBC-RS'1; Luisa Jussara Coelho'; Edson Braga Lameu'; Antonio Carlos Weston, TCBC-RS'; LUIS Fernando Moreira, TCBC-RS'1.

\section{A B S T R A C T}

\begin{abstract}
Objectives: to determine the nutritional evaluation method that best predicts mortality in 90 days of patients submitted to gastrectomy for gastric cancer. Methods: we conducted a prospective study with 44 patients with gastric cancer, stages II to IIla, of whom nine were submitted to partial gastrectomy, 34 to total gastrectomy, and one to esophago-gastrectomy. All patients were nutritionally evaluated through the same protocol, up to $72 \mathrm{~h}$ after hospital admission. The parameters used were Patient-Generated Subjective Global Assessment (PGSGA), classical anthropometry, current weight and height, percentage of weight loss (\%WL) and body mass index (BMI). We also measured the thickness of the thumb adductor muscle (TAM) in both hands, dominant hand (TAMD) and non-dominant hand (TAMND), as well as the calculated the prognostic nutritional index (PNI). The laboratory profile included serum levels of albumin, erythrocytes, hemoglobin, hematocrit, leukocytes, and total lymphocytes count (TLC). Results: of the 44 patients studied, 29 (66\%) were malnourished by the subjective method, 15 being grade $A, 18$ grade $B$ and 11 grade $C$. Cases with PGSGA grade $B$ and TAMD 10.2 \pm 2.9 mm were significantly associated with higher mortality. The ROC curves (95\% confidence interval) of both PGSGA and TAMD thickness reliably predicted mortality at 30 and 90 days. No laboratory method allowed predicting mortality at 90 days. Conclusion: PGSGA and the TAMD thickness can be used as preoperative parameters for risk of death in patients undergoing gastrectomy for gastric cancer.
\end{abstract}

Keywords: Nutrition Assessment. Stomach Neoplasms. Mortality. Prognosis.

\section{INTRODUCTION}

\begin{abstract}
A Ithough with decreasing incidence and mortality in many countries in the last decades, gastric cancer is still common worldwide and its prognosis is poor $^{1-4}$. Gastrectomy is the only potentially curative treatment, but it is associated with increased postoperative catabolism and metabolic, endocrine, neuroendocrine and immune changes that contribute to high postoperative morbidity rates ${ }^{5-6}$.

Patients with gastric cancer have a high risk of malnutrition, with a weight loss greater than $10 \%$ in the last six months reported in 30\% to 38\% of cases $^{5}$. Malnutrition, defined as a state of deficiency of energy, protein and other specific nutrients, has a negative impact on clinical outcome, with a longer hospital stay and increased mortality ${ }^{7}$. A thorough screening for malnutrition is very important, sin-
\end{abstract}

ce preoperative nutritional interventions can restore nutritional status and improve surgical outcomes ${ }^{8-11}$. However, nutritional assessment is known to be particularly difficult, since none of the currently used methods or instruments alone or in combination have proven to be adequate to increase its sensitivity and specificity ${ }^{11-13}$.

Regarding evaluation of therapy, no quality measure is as precise, easily quantifiable and important as postoperative mortality ${ }^{1}$. Thirty-day mortality (30DM) is the commonly used parameter, but 90-day mortality (90DM) has been increasingly recognized as a more reliable indicator in many surgical procedures, since 30DM is believed to underestimate total mortality in cases of debilitating, aggressive and advanced tumors of the upper gastrointestinal tract ${ }^{14}$.

The objective of this study was to prospectively evaluate the method of nutritional evaluation

1 - Federal University of Rio Grande do Sul, Post-Graduation Program in Surgical Sciences, Porto Alegre, RS, Brazil. 
that best predicts mortality in 90 days of patients undergoing gastrectomy for gastric cancer.

\section{METHODS}

We carried out a prospective study based on a convenience sample that included 44 patients, 29 males and 15 females, mean age $63( \pm 10.2)$ years (range 34-83), who underwent gastrectomy at the Santa Rita Hospital of Santa Casa de Misericórdia, Porto Alegre, RS, Brazil, from March 2009 to March 2011. All were aware of the study and agreed to participate. We obtained a signed informed consent form from all participants. This study is part of the research line of the Southern Surgical Oncology Research Group (SSORG) and was approved by the Ethics in Research Committee under number 2,041/08 of the Holy Home of Mercy of Porto Alegre.

We evaluated the nutrition status of all patients through the same protocol, up to 72 hours after hospital admission. The parameters used were the Patient-Generated Subjective Global Assessment (PGSGA), classical anthropometry, current weight and height, percentage of weight loss (\%WL) and body mass index (BMI). We also measured the thickness of the thumb adductor muscle (TAM) in both hands, dominant hand (TAMD) and non-dominant one (TAMND). The laboratory profile included serum levels of albumin, erythrocytes, hemoglobin, hematocrit, leukocytes, and total lymphocytes count (TLC). We calculated the prognostic nutritional index (PNI) using the following formula: $10 x$ serum albumin value $(\mathrm{g} / \mathrm{dl})$ $+0.005 x$ total lymphocytes count in the peripheral blood $\left(\text { per } \mathrm{mm}^{3}\right)^{6}$.

We used Portuguese-validated versions of the PGSGA, adapted by Ottery ${ }^{15}$, specific for cancer patients, to evaluate the nutritional status. These results were categorically classified as A, B or C, for well nourished, moderately or severely malnourished, respectively. We used the sum of the scores to determine specific nutritional approaches ${ }^{16}$. We routinely checked the current weight and height with a pre-calibrated platform-type digital scale and a measuring rod. We used the tables proposed by Lipschitz et al. ${ }^{16}$ and by the World Health Organization (WHO) ${ }^{17}$ to classify the body mass index (BMI) of elderly and adult patients, respectively. We considered the usual weight as reported by the patients to determine the percentage of weight loss. We measured TAM thickness with an adipometer, by compressing the thumb adductor muscle at the apex of an imaginary triangle formed by the extension of the thumb and index finger ${ }^{18}$.

A single trained nutritionist evaluated all of these anthropometric measures, attempting to reduce bias. All measurements were performed in triplicate and the results presented as the average of three measurements.

Statistical analysis included relative counts and frequencies, as well as measures of central tendency (mean and median) and variability (standard deviation and interquartile range), which we used whenever necessary. We used the Kolmogorov-Smirnov test to evaluate the symmetry of the distribution, and performed the comparison of categorical data with the Fisher's exact test or Monte Carlo simulation for alternative outcomes, when necessary. In the bivariate analysis, we compared continuous variables between the two independent groups with the Student's $t$ or the Mann-Whitney tests. We determined the linear relationship between parametric and non-parametric continuous variables with the Pearson or Spearman correlation, respectively. We used the Receiver Operating Characteristic (ROC) curve to determine if subjective, anthropometric and laboratory variables correlated with mortality. We used the SPSS program (Statistical Package Social Sciences for Windows) 17.0 to analyze the data, considering a $95 \%$ confidence interval and significance level of $p<0.05$.

\section{RESULTS}

Of the 44 patients evaluated, nine (20.4\%) underwent partial gastrectomy, 34 (77.3\%) total gastrectomy and one (2.3\%) esophago-gastrectomy. Stages ranged from II to IIIa, with a predominance of stage III, according to the AJCC 2010 classification, which, in a univariate analysis, did not reveal a significant difference in relation to mortality. Patient characteristics and mortality are shown in table 1. 
Table 1. Description of the sample according to mortality $(n=44)$.

\begin{tabular}{|c|c|c|c|c|c|}
\hline \multirow{3}{*}{ Variables } & \multicolumn{3}{|c|}{ Death } & \multicolumn{2}{|l|}{$p$} \\
\hline & Alive $(n=31)$ & $\begin{array}{l}\text { Death within } 30 \text { days ( } \\
=6 \text { ) }\end{array}$ & $\begin{array}{c}\text { Death within } 90 \text { days ( } \mathrm{n} \\
=13 \text { ) }\end{array}$ & \multirow{2}{*}{$\begin{array}{l}\text { Death within } \\
30 \text { days }^{A}\end{array}$} & \multirow{2}{*}{$\begin{array}{l}\text { Death } \\
\text { within } 90 \\
\text { days }^{\mathrm{B}}\end{array}$} \\
\hline & $\%$ & $\%$ & $\%$ & & \\
\hline \multicolumn{6}{|l|}{ Gender } \\
\hline Male & 67.7 & 66.7 & 61.5 & $>0.999+$ & $0.098+$ \\
\hline Female & 32.3 & 33.3 & 38.5 & & \\
\hline $\begin{array}{l}\text { Age (Mean } \\
\pm \text { Sd) }\end{array}$ & $60.4 \pm 11.2$ & $62.7 \pm 9.5$ & $64.1 \pm 9.4$ & $0.7813^{*}$ & $0.375^{*}$ \\
\hline $\mathrm{BMl}$ & $23.7 \pm 3.6$ & $18.4 \pm 3.4$ & $22.2 \pm 5.2$ & $0.003^{*}$ & $0.463^{*}$ \\
\hline (elderly) & $25.0 \pm 3.7$ & $19.8 \pm 0.1$ & $24.9 \pm 4.1$ & $0.043^{*}$ & $0.980 *$ \\
\hline (adults) & $22.8 \pm 3.2$ & $17.7 \pm 4.2$ & $19.1 \pm 4.8$ & $0.013^{*}$ & $0.035^{\star}$ \\
\hline$\% \mathrm{WL} / 6 \mathrm{~m}$ & $12.1 \pm 11.2$ & $26.8 \pm 17.4$ & $18.5 \pm 14.5$ & $0.092+$ & $0.102+$ \\
\hline TAMD & $14.9 \pm 3.1$ & $8.5 \pm 1.9$ & $10.2 \pm 2.9$ & $<0.001 *$ & $<0.001$ * \\
\hline TAMND & $13.6 \pm 3.3$ & $7.3 \pm 1.7$ & $9.4 \pm 3.5$ & $<0.001$ * & $0.002^{*}$ \\
\hline Albumin & $3.9 \pm 0.4$ & $3.4 \pm 0.8$ & $3.7 \pm 0.7$ & $0.265^{*}$ & $0.257 *$ \\
\hline Hemoglobin & $12.8 \pm 2.2$ & $12.8 \pm 2.4$ & $12.2 \pm 1.8$ & $0.900 *$ & $0.102^{*}$ \\
\hline Hematocrit & $38.0 \pm 5.4$ & $37.2 \pm 6.3$ & $36.1 \pm 4.9$ & $0.577^{*}$ & $0.058^{*}$ \\
\hline $\mathrm{TLC}$ & $1587.6 \pm 608.1$ & $1414.8 \pm 553.1$ & $1578.7 \pm 623.6$ & $0.482+$ & $0.945+$ \\
\hline $\mathrm{PNI}$ & $47.9 \pm 6.1$ & $41.4 \pm 10.4$ & $44.7 \pm 8.5$ & $0.209 *$ & $0.398^{*}$ \\
\hline
\end{tabular}

A: minimum level of significance in the comparison between the groups "alive vs. death within 30 days"; B: minimum level of significance in the comparison between the groups "alive vs. death within 90 days"; BMI: body mass index; \% WL/6 m: percentage of weight loss in the last six months; TAMD: Thumb Adductor Muscle of the dominant hand; TAMND: Thumb Adductor Muscle of the non-dominant hand; TLC: total lymphocytes count; PNI: prognostic nutritional Index; * Fisher's exact test (by Monte Carlo simulation); + Kruskal Wallys and one-way analysis of variance Post Hoc Sheffé, where means followed by letters point out significant difference of $5 \%$.

One third of the patients had some degree of malnutrition and 11 (25\%) of them were severely malnourished. The length of hospital stay was on average $24( \pm 21)$ days. Thirteen $(29.5 \%)$ patients died within the first three postoperative months, and the most frequent causes were anastomosis and sepsis dehiscence in six $(46.1 \%)$ and acute respiratory failure in four $(30.8 \%)$.

Differences in the PGSGA were not statistically significant $(c 2 c a l c=1.682, p=0.431)$. However, the proportion of patients with weight loss over $10 \%$ at six months $(n=26 ; 59.1 \%)$ was significant in this sample $(\mathrm{c} 2 \mathrm{cal} \mathrm{c}=46.7 ; \mathrm{p}<0.001)$. Of the 13 patients who died, 12 (92.3\%) were diagnosed as grade B or $C$ by the PGSGA, while 14 (45.2\%) of those who survived were diagnosed as grade $A$ and $12(38.7 \%)$ as grade $B(p=0.025)$.

Regarding the TAM thickness, there was no statistically significant difference observed between the dominant and non-dominant hands $(p<0.02)$. The TAM thickness in the dominant hand (TAMD) was the best parameter capable of predicting death (Table 2). 
All patients who died within the first three postoperative months were significantly more malnourished as demonstrated by the TAMD (Table 2). Although albu- min was decreased in the malnourished patients who died, no laboratory method predicted 90-day mortality with statistical strength (Table 3).

Table 2. Anthropometric parameters and 90-days postoperative mortality.

\begin{tabular}{|c|c|c|c|c|c|c|c|c|c|c|c|}
\hline \multirow{3}{*}{$\begin{array}{c}\text { Anthropometric } \\
\text { Method }\end{array}$} & \multicolumn{10}{|c|}{ Mortality at 90 days $(n=44)$} & \multirow{3}{*}{$p$} \\
\hline & \multicolumn{5}{|c|}{ Death $(n=13)$} & \multicolumn{5}{|c|}{ No death $(n=31)$} & \\
\hline & Mean & SD & Median & $\mathrm{P} 25$ & P 75 & Mean & SD & Median & P25 & P 75 & \\
\hline BMI $\left(\mathrm{kg} / \mathrm{m}^{2}\right)$ & 22.2 & 5.2 & 22.7 & 18.4 & 26.6 & 23.7 & 3.6 & 23.4 & 21.5 & 26.5 & $0.463^{*}$ \\
\hline$\% W L / 6 \mathrm{~m}$ & 18.5 & 14.5 & 16.4 & 11.4 & 18.8 & 12.1 & 11.2 & 11.0 & 3.1 & 16.7 & $0.102+$ \\
\hline TAMD & 10.2 & 2.9 & 9.7 & 8.5 & 12.8 & 14.9 & 3.1 & 15.3 & 13.0 & 16.7 & $0.001 *$ \\
\hline TAMND & 9.4 & 3.5 & 8.3 & 7.7 & 12.0 & 13.6 & 3.3 & 13.7 & 11.7 & 16.0 & $0.002 *$ \\
\hline
\end{tabular}

Table 3. Laboratory Parameters and 90-days postoperative mortality.

\begin{tabular}{|c|c|c|c|c|c|c|c|c|c|c|c|}
\hline \multirow{3}{*}{$\begin{array}{l}\text { Laboratory } \\
\text { Method }\end{array}$} & \multicolumn{10}{|c|}{ Mortality at 90 days } & \multirow{3}{*}{$p$} \\
\hline & \multicolumn{5}{|c|}{ Death $(n=13)$} & \multicolumn{5}{|c|}{ No death $(n=31)$} & \\
\hline & Mean & SD & Median & P25 & P 75 & Mean & SD & Median & P25 & P 75 & \\
\hline Albumin (g/dl) & 3.7 & 0.7 & 3.8 & 3.3 & 4.2 & 3.9 & 0.4 & 3.9 & 3.6 & 4.3 & $0.257 *$ \\
\hline $\begin{array}{l}\text { Hemoglobin (g/ } \\
\mathrm{dl})\end{array}$ & 12.2 & 1.8 & 12.3 & 11.2 & 13.1 & 12.8 & 2.2 & 13.2 & 12.3 & 14.3 & $0.102 *$ \\
\hline Hematocrit (\%) & 36.2 & 5.0 & 35.9 & 32.8 & 38.5 & 38.0 & 5.4 & 38.5 & 36.3 & 41.1 & $0.058 *$ \\
\hline $\operatorname{TLC}(\mathrm{g} / \mathrm{dl})$ & 1578.7 & 623.6 & 1655.1 & 852.1 & 2125.7 & 1587.6 & 608.1 & 1387 & 1093 & 2048 & $0.945 *$ \\
\hline PNI & 44.7 & 8.5 & 46.8 & 40.3 & 51.2 & 47.9 & 6.1 & 47.6 & 43.1 & 51.8 & $0.398 *$ \\
\hline
\end{tabular}

TLC : total lymphocytes count; PNI: prognostic nutritional Index; * Student's t test for independent groups.

Table 4 presents data on laboratory parameters and postoperative mortality, in which the PGSGA $(p<0.001)$, TAMD $(p<0.001)$ and albumin $(p=0.026)$ predicted mortality at 30 days. However, only the PGSGA showed significance in predicting 90-day mortality $(p=0.047)$.

It is worth noting that there was no statistically significant difference in TAM values in relation to gender, either in the dominant hand (Female: $12.6 \pm$ 3.4 vs. Male: $14.2 \pm 3.9, p=0.157$ ) or in the non-do- minant one (Female: $11.6 \pm 3.6$ vs. Male: $12.9 \pm 3.9$, $p=0.265)$.

The predictive power calculated by the area below the ROC curve was statistically significant for PGSGA (0.833), BMI (0.857), TAMD (0.874) and TAM$\mathrm{ND}(0.755)$, with the highest prediction powers concentrated on TAMD $(p=0.006)$ and PGSGA $(p=0.008)$, as shown in table 5 . Significant estimates for areas under the curve of variables as predictors of mortality are shown around 0.70 . 
Table 4. Nutritional Parameters and postoperative mortality.

\begin{tabular}{|c|c|c|c|c|c|c|}
\hline \multirow[t]{2}{*}{ Variables } & \multicolumn{2}{|c|}{$\begin{array}{c}\text { Death within } 30 \text { days } \\
(n=6-13.6 \%)\end{array}$} & \multirow[t]{2}{*}{$p$} & \multicolumn{2}{|c|}{$\begin{array}{l}\text { Death within } 90 \text { days } \\
(n=13-29.5 \%)\end{array}$} & \multirow[t]{2}{*}{$p$} \\
\hline & Yes $(n=6)$ & No $(n=38)$ & & Yes $(n=13)$ & No $(n=31)$ & \\
\hline BMI & $18.4 \pm 3.4$ & $24.1 \pm 3.7$ & $0.001 *$ & $22.4 \pm 5.2$ & $23.7 \pm 3.6$ & 0.463 \\
\hline TAMD* & $8.5 \pm 1.9$ & $14.3 \pm 3.3$ & $<0.001 *$ & $10.1 \pm 2.9$ & $14.9 \pm 3.1$ & $0.001 *$ \\
\hline TAMND & $7.3 \pm 1.7$ & $13.2 \pm 3.4$ & $<0.001 *$ & $9.4 \pm 3.5$ & $13.6 \pm 3.3$ & $0.002 *$ \\
\hline Albumin & $3.4 \pm 0.8$ & $4.0 \pm 0.4$ & $0.026^{*}$ & $3.7 \pm 0.7$ & $3.9 \pm 0.4$ & $0.257 *$ \\
\hline TLC & $1414.8 \pm 553.1$ & $\begin{array}{l}1613.9 \pm \\
616.4\end{array}$ & 0.463 & $\begin{array}{l}1578.7 \pm \\
623.6\end{array}$ & $1587.6 \pm 608.1$ & $0.945+$ \\
\hline PNI & $41.4 \pm 10.4$ & $47.9 \pm 6.0$ & $0.035 *$ & $44.7 \pm 8.5$ & $47.9 \pm 6.1$ & $0.398 *$ \\
\hline \multicolumn{7}{|l|}{ PGSGA } \\
\hline (A) & $0(0.0 \%)$ & $15(39.5 \%)$ & & $1(7.7 \%)$ & $14(45.4 \%)$ & \\
\hline (B) & $0(0.0 \%)$ & $18(47.4 \%)$ & $<0.001+$ & $6(46.6 \%)$ & $12(38.7 \%)$ & $0.025+$ \\
\hline (C) & $6(100.0 \%)$ & $5(13.2 \%)$ & & $6(46.2 \%)$ & $516.1 \%)$ & \\
\hline
\end{tabular}

TAMD : Thumb adductor muscle of the dominant hand; TAMND: Thumb adductor muscle of the non-dominant hand; TLC: total lymphocytes count; PNI: prognostic nutritional Index; PGSGA: Patient-Generated Subjective Global Assessment; * Student's t test for independent groups; + Mann Whitney test + Fisher exact test (Monte Carlo simulation).

Table 5. Area under the ROC curve of cutoff for predictors of mortality parameters within 30 and 90 days post gastrectomy.

ROC Curve-Mortality

Parameters

Area under the curve

$(95 \% \mathrm{Cl})$

p

Cut-off point

Death within 30 days

Subjective

PGSGA

$0.833(0.763-0.956)$

0.008

(B)

Anthropometrical

$\mathrm{BMI}$

$0.857(0.722-0.992)$

0.021

$>22.6$

TAMD

$0.874(0.763-0.948)$

0.006

$=11.2$

TAMND

$0.755(0.617-0.822)$

0.037

$=8.4$

Laboratory

Albumin

$0.652(0.368-0.877)$

0.238

$=3.3$

PNI

$0.667(0.410-0.923)$

0.197

$<43.6$

Death within 90 days

Subjective

PGSGA

$0.739(0.653-0.845)$

0.036

(B)

Anthropometrical

$\begin{array}{clll}\text { TAMD } & 0.866(0.774-0.992) & 0.024 & =10.7 \\ \text { TAMND } & 0.805(0.688-0.922) & 0.041 & =9.7\end{array}$

PGSGA: Patient-Generated Subjective Global Assessment; BMI: body mass index; TAMD: Thumb adductor muscle thickness of the dominant hand; TAMND: Thumb adductor muscle thickness of the non-dominant hand; PNI: prognostic nutritional Index. 


\section{DISCUSSION}

The consumptive process occurs according to a cascade of events and is independent of the size of the surgical procedure, which explains the most expressive and evidenced mortality in the most malnourished patients ${ }^{10}$. Anastomosis dehiscence in patients with poorer nutritional status and with more advanced age is an independent factor of worse prognosis ${ }^{19}$, considerably worsening the incidence of postoperative death in patients with gastric tumor.

Significant weight loss is generally seen in patients with incurable solid tumors ${ }^{8,20}$, as observed in our results. Gavazzi et al. ${ }^{21}$ found weight loss over $5 \%$ in the previous three months in 35\% of patients recently diagnosed with gastric carcinoma. Rey-Ferro et al. ${ }^{22}$ found an average of $10 \%$ weight loss, and in those who died postoperatively, weight loss had been significantly higher than in those who survived $(p=0.06)$. These results were also confirmed in the study by Shim et al. ${ }^{6}$, in which preoperative weight loss $(p=0.008)$ and gastric cancer $(p<0.001)$ were independent risk factors for severe malnutrition.

Recently, Gonzalez et al. ${ }^{23}$ reported that TAM thickness was significantly associated with nutritional status in a sample of surgical patients in southern Brazil. We found similar results, the lowest TAM thickness being related to higher mortality, as also demonstrated by Melo and Silva ${ }^{24}$ in 151 elective procedures and Bragagnolo 25 in 87 large procedures of the upper gastrointestinal tract, all in Brazil.

In the present study, almost two-thirds (67\%) of the patients were malnourished by PGSGA, similar to other studies, showing malnutrition rates of $66 \%$ and $57 \% 26,27$, but lower than the $86 \%$ and $88 \%$ described in other works ${ }^{24-25}$. Paceli et al. ${ }^{28}$ found a preoperative weight loss greater than $10 \%$ in $42 \%$ of gastric cancer patients, similar to those of other Asian studies, of $13 \%$ and $31 \% 6,7$, respectively. However, this incidence may increase to $81 \%$ in the postoperative period, which confirms that gastrectomy significantly affects nutrition ${ }^{20,29}$. Probably, these differences between South American and Asian studies are due to differences in the higher prevalence of early stage disease in Asian countries, when nutrition is not yet significantly impaired.

Nutritional status has long been associated with immunocompetence, complications, and infections. Yamanaka et al. ${ }^{30}$, in 1980, demonstrated that serum albumin and prealbumin predicted better preoperative nutritional status than standard anthropometry in 413 patients with gastric cancer ( $40 \%$ of stage IV cases). In their study, Rey-Ferro et al. ${ }^{22}$ argue that hypoalbuminemia and weight loss have a positive predictive value for mortality in patients with gastric cancer. In a multicenter US Gastric Cancer Collaborative study involving 775 patients undergoing gastrectomy, Ejaz et al. ${ }^{31}$ observed that $\mathrm{BMI}<18.5 \mathrm{~kg} / \mathrm{m}^{2}$ and low levels of albumin were related to a significant decrease in overall survival after gastrectomy. However, in our study, it was not possible to significantly associate these parameters with mortality, suggesting that albumin and serum protein parameters may not be as sensitive as anthropometric measures for nutritional status.

The Glasgow prognostic score (GPS) is a significant predictor of long-term survival in patients with curable gastric cancer, but not for short-term evaluations $^{32,33}$. A Brazilian group found a relationship between PGSGA and GPS, and both measures were associated with postoperative complications and survival in patients with esophageal and stomach cancer ${ }^{29}$. An ongoing study in our research group is evaluating the role of GPS as a short-term predictor of worsening nutritional status and postoperative complications.

The prognostic nutritional index (PNI) has been advocated as a good predictor of postoperative morbidity, prognosis and recurrence patterns in patients in Asian studies, ${ }^{5,34}$. In a recent update of nutrition in patients with gastric cancer, $\mathrm{PNI}$, or a combination of preoperative $\mathrm{BMl}<18.5 \mathrm{~kg} / \mathrm{m}^{2}$ and low albumin levels, appear as predictors of decreased overall survival after gastrectomy 9 . In the present study we did not find statistical significance capable of proving the prediction of mortality.

In our study, 30-day mortality was highly correlated with TAM thickness ( $p<0.001$ ), PGSGA $(p<0.001)$ and albumin $(p=0.026)$, these parameters not being related to outcomes in 90 days, except for PGSGA ( $p=0.047)$. These results were confirmed by the ROC curve, with the area under the curve (AUC) better correlated with TAM thickness $(p=0.003)$ than PGSGA $(p=0.013)$ and much better than albumin $(p=0.097)$. 
The failure to demonstrate the significance of these parameters as for the risk of death in 90 days is probably due to the patients having been submitted to pre and postoperative nutritional support. However, these 90-day mortality results require confirmation in larger series.

According to Tegels et al. ${ }^{4}$, the evidence for the value of nutritional screening tools in the prediction of gastric cancer surgery postoperative outcomes is scarce. Considering PGSGA as a gold standard and comparing it with other methods of nutritional assessment in patients with gastric and colorectal cancer, Abe Vicente et al. ${ }^{26}$ found a better association with the MUST tool $(p<0.001)$ and suggested Combination of both methods as a good assessment of nutritional status. However, these assessments based on questionnaires may be more difficult to perform in our country, since the vast majority of patients have low educational level.

In a study of 751 patients diagnosed with gastrointestinal cancer (51\% of gastric cancer), Wu et al. ${ }^{35}$ found a higher incidence of complications and longer hospital stay according to the increase in PGSGA levels in patients undergoing surgery or who received chemotherapy/radiotherapy, also observed in our study. Although similar rates of postoperative complications were observed in patients with different degrees of weight loss, albumin and BMI, there was no difference in the incidence of anastomosis dehiscence (greater in patients with weight loss greater than $10 \%$, serum albumin $<3.0 \mathrm{~g} / \mathrm{dl}$, or $\mathrm{BMl}<18.5 \mathrm{~kg} / \mathrm{m}^{2}$ ). Similarly, in other articles ${ }^{6,23-26}$ on nutritional assessment in gastric cancer patients that also include patients with colorectal cancer, the results may not reliably demonstrate changes in nutritional status, since tumor development and nutritional status are quite distinct between tumors of the lower and upper gastrointestinal tract. In addition, a wide variety of methods have been used to assess nutritional status in each study, which challenges subsequent comparison 5,23,29,30,35. We believe in the need of a more specific nutritional evaluation for these surgical oncology patients with tumors of the gastrointestinal tract, which allows the early identification of nutritional changes, is necessary. With it, a nutritional intervention could be established early to improve postoperative results and decrease mortality rates. There is an ongoing nutritional risk assessment by a combination of weight loss, gastrointestinal signs and symptoms, pain score, GPS, performance status, and implications of oncological treatments measured in a larger sample.

The methods evaluated in our study showed a greater prediction of mortality in 30 days. Further studies to determine the best predictors of mortality in 90 days should be performed. On the other hand, the present study indicates that the dominant hand TAM thickness and the PGSGA are reliable prediction parameters of mortality both in 30 and in 90 days in patients submitted to gastrectomy due to stomach cancer.

\title{
R E S U M O
}

\begin{abstract}
Objetivos: determinar o método de avaliação nutricional que melhor prediz a mortalidade em 90 dias de pacientes submetidos à gastrectomia por câncer gástrico. Métodos: estudo prospectivo de 44 pacientes portadores de câncer gástrico, estágios II a IIIa, dos quais nove foram submetidos à gastrectomia parcial, 34 à gastrectomia total e um à esôfago-gastrectomia. Todos os pacientes foram avaliados nutricionalmente através do mesmo protocolo, até $72 \mathrm{~h}$ da admissão hospitalar. Os parâmetros utilizados foram a Avaliação Subjetiva Global Produzida Pelo Paciente (ASG-PPP), antropometria clássica, incluindo peso e altura atuais, porcentagem de perda ponderal (\%PP) e índice de massa corporal (IMC). A espessura do músculo adutor do polegar (MAP) em ambas mãos, mão dominante (MAPD) e mão não-dominante (MAPND) também foram realizadas, assim como o cálculo do índice nutricional prognóstico (IPN). O perfil laboratorial incluiu níveis séricos de albumina, eritrócitos, hemoglobina, hematócrito, leucócitos e contagem total de linfócitos (CTL). Resultados: dos 44 pacientes estudados, 29 (66\%) eram desnutridos pelo método subjetivo, sendo 15 grau A, 18 grau B e 11 grau C. Os casos com ASG-PPP grau B e com MAPD 10,2 $\pm 2,9 \mathrm{~mm}$ foram significativamente associados à maior mortalidade. As curvas ROC (intervalo de confiança de 95\%) de ambas ASG-PPP e espessura da MAPD fidedignamente predisseram mortalidade em 30 e 90 dias. Nenhum método laboratorial permitiu prever a mortalidade em 90 dias. Conclusão: a ASG-PPP e a espessura da MAPD podem ser utilizados como parâmetros pré-operatórios para risco de morte em pacientes submetidos à gastrectomia por câncer gástrico.
\end{abstract}

Descritores: Avaliação Nutricional. Neoplasias Gástricas. Mortalidade. Prognóstico. 


\section{REFERENCES}

1. Ferro A, Peleteiro B, Malvezzi M, Bosetti C, Bertuccio $\mathrm{P}$, Levi $\mathrm{F}$, et al. Worldwide trends in gastric cancer mortality (1980-2011), with predictions to 2015 , and incidence by subtype. Eur J Cancer. 2014;50(7):133044.

2. Piazuelo MB, Correa P. Gastric cancer: overview. Colomb Med (Cali). 2013;44(3):192-201.

3. Bertuccio P, Chatenoud L, Levi F, Praud D, Ferlay J, Negri $E$, et al. Recent patterns in gastric cancer: a global overview. Int J Cancer. 2009;125(3):666-73.

4. Tegels JJ, De Maat MF, Hulsewé KW, Hoofwijk AG, Stoot JH. Improving the outcomes in gastric cancer surgery. World J Gastroenterol. 2014;20(38):13692704.

5. Jiang N, Deng JY, Ding XW, Ke B, Liu N, Zhang RP, et al. Prognostic nutritional index predicts postoperative complications and long-term outcomes of gastric cancer. World J Gastroenterol. 2014;20(30):1053744.

6. Shim $H$, Cheong JH, Lee KY, Lee H, Lee JG, Noh $\mathrm{SH}$. Perioperative nutritional status changes in gastrointestinal cancer patients. Yonsei Med J. 2013;54(6):1370-6.

7. Ryu SW, Kim IH. Comparison of different nutritional assessments in detecting malnutrition among gastric cancer patients. World J Gastroenterol. 2010;16(26):3310-7.

8. Andreoli A, De Lorenzo A, Cadeddu F, lacopino L, Grande M. New trends in nutritional status assessment of cancer patients. Eur Rev Med Pharmacol Sci. 2011;15(5):469-80.

9. Rosania R, Chiapponi C, Malfertheiner P, Venerito M. Nutrition in patients with gastric cancer: an update. Gastrointest Tumors. 2016;2(4):178-87.

10. Poziomyck AK, Fruchtenicht AV, Kabke GB, Volkweis BS, Antoniazzi JL, Moreira LF. Reliability of nutritional assessment in patients with gastrointestinal tumors. Rev Col Bras Cir. 2016;43(3):189-97.

11. Sungurtekin $H$, Sungurtekin $U$, Balci $C$, Zencir $M$, Erdem $E$. The influence of nutritional status on complications after major intraabdominal surgery. J Am Coll Nutr. 2004;23(3):227-32.

12. Pablo AM, Izaga MA, Alday LA. Assessment of nutritional status on hospital admission: nutritional scores. Eur J Clin Nutr. 2003;57(7):824-31.

13. Damhuis RA, Wijnhoven BP, Plaisier PW, Kirkels WJ, Kranse R, van Lanschot JJ. Comparison of 30-day, 90day and in-hospital postoperative mortality for eight different cancer types. Br J Surg. 2012;99(8):114954.

14. Gonzalez MC, Borges LR, Silveira DH, Assunção MCF, Orlandi SP. Validação da versão em português da avaliação subjetiva global produzida pelo paciente. . Rev Bras Nutr Clin. 2010;25(2):102-8.

15. Ottery FD. Definition of standardized nutritional assessment and interventional pathways in oncology. Nutrition. 1996;12(1 Suppl):S15-9.

16. Lipschitz DA. Screening for nutritional status in the elderly. Prim Care. 1994;21(1):55-67.

17. 17. Obesity: preventing and managing the global epidemic. Report of a WHO consultation. World Health Organ Tech Rep Ser. 2000;894:i-xii, 1-253.

18. Lameu EB, Gerude MF, Campos AC, Luiz RR. The thickness of the adductor pollicis muscle reflects the muscle compartment and may be used as a new anthropometric parameter for nutritional assessment. Curr Opin Clin Nutr Metab Care. 2004;7(3):293-301.

19. Toneto MG, Moreira LF, Jeckel Neto E, Souza HP. Gastrectomia em pacientes idosos: análise dos fatores relacionados a complicações e mortalidade. Rev Col Bras Cir. 2004;31(6):373-9.

20. Mariette C, De Botton ML, Piessen G. Surgery in esophageal and gastric cancer patients: what is the role for nutrition support in your daily practice? Ann Surg Oncol. 2012;19(7):2128-34.

21. Gavazzi C, Colatruglio S, Sironi A, Mazzaferro $\mathrm{V}$, Miceli R. Importance of early nutritional screening in patients with gastric cancer. Br J Nutr. 2011;106(12):1773-8.

22. Rey-Ferro M, Castaño R, Orozco O, Serna A, Moreno A. Nutritional and immunologic evaluation of patients with gastric cancer before and after surgery. Nutrition. 1997;13(10):878-81.

23. Gonzalez MC, Pureza Duarte RR, Orlandi SP, Bielemann RM, Barbosa-Silva TG. Adductor pollicis muscle: a study about its use as a nutritional parameter in surgical patients. Clin Nutr. 2015;34(5):1025-9. 
24. Melo CY, Silva SA. Adductor pollicis muscle as predictor of malnutrition in surgical patients. Arq Bras Cir Dig. 2014;27(1):13-7.

25. Bragagnolo R, Caporossi FS, Dock-Nascimento DB, de Aguilar-Nascimento JE. [Adductor pollicis muscle thickness: a fast and reliable method for nutritional assessment in surgical patients]. Rev Col Bras Cir. 2009;36(5):371-6. Portuguese.

26. Abe Vicente $M$, Barão $K$, Silva TD, Forones NM. What are the most effective methods for assessment of nutritional status in outpatients with gastric and colorectal cancer? Nutr Hosp. 2013;28(3):585-91.

27. Dias Rodrigues $V$, Barroso de Pinho N, Abdelhay E, Viola JP, Correia MI, Brum Martucci R. Nutrition and immune-modulatory intervention in surgical patients with gastric cancer. Nutr Clin Pract. 2017;32(1):1229. Epub 2016 Jul 9.

28. Pacelli F, Bossola M, Rosa F, Tortorelli AP, Papa $V$, Doglietto GB. Is malnutrition still a risk factor of postoperative complications in gastric cancer surgery? Clin Nutr. 2008;27(3):398-407.

29. da Silva JB, Mauricio SF, Bering T, Correia MI. The relationship between nutritional status and the Glasgow prognostic score in patients with cancer of the esophagus and stomach. Nutr Cancer. 2013;65(1):25-33.

30. Yamanaka H, Nishi M, Kanemaki T, Hosoda N, Hioki K, Yamamoto M. Preoperative nutritional assessment to predict postoperative complication in gastric cancer patients. JPEN J Parenter Enteral Nutr. 1989;13(3):286-91.

31. Ejaz A, Spolverato G, Kim Y, Poultsides GA, Fields RC, Bloomston $\mathrm{M}$, et al. Impact of body mass index on perioperative outcomes and survival after resection for gastric cancer. J Surg Res. 2015;195(1):74-82.

32. Kubota T, Hiki N, Nunobe S, Kumagai K, Aikou S, Watanabe $R$, et al. Significance of the inflammationbased Glasgow prognostic score for short- and longterm outcomes after curative resection of gastric cancer. J Gastrointest Surg. 2012;16(11):2037-44.

33. Fukuda $Y$, Yamamoto $K$, Hirao $M$, Nishikawa K, Maeda S, Haraguchi N, et al. Prevalence of malnutrition among gastric cancer patients undergoing gastrectomy and optimal preoperative nutritional support for preventing surgical site infections. Ann Surg Oncol. 2015;22 Suppl 3:77885.

34. 3Kanda M, Mizuno A, Tanaka C, Kobayashi D, Fujiwara $M$, Iwata $N$, et al. Nutritional predictors for postoperative short-term and long-term outcomes of patients with gastric cancer. Medicine (Baltimore). 2016;95(24):e3781.

35. Wu BW, Yin T, Cao WX, Gu ZD, Wang XJ, Yan $M$, et al. Clinical application of subjective global assessment in Chinese patients with gastrointestinal cancer. World J Gastroenterol. 2009;15(28):3542-9.

Received in: 25/04/2017

Accepted for publication: 01/06/2017

Conflict of interest: none.

Source of funding: none.

\section{Mailing address:}

Aline Kirjner Poziomyck

E-mail: akirjner@yahoo.com.br / akirjner@gmail.com 